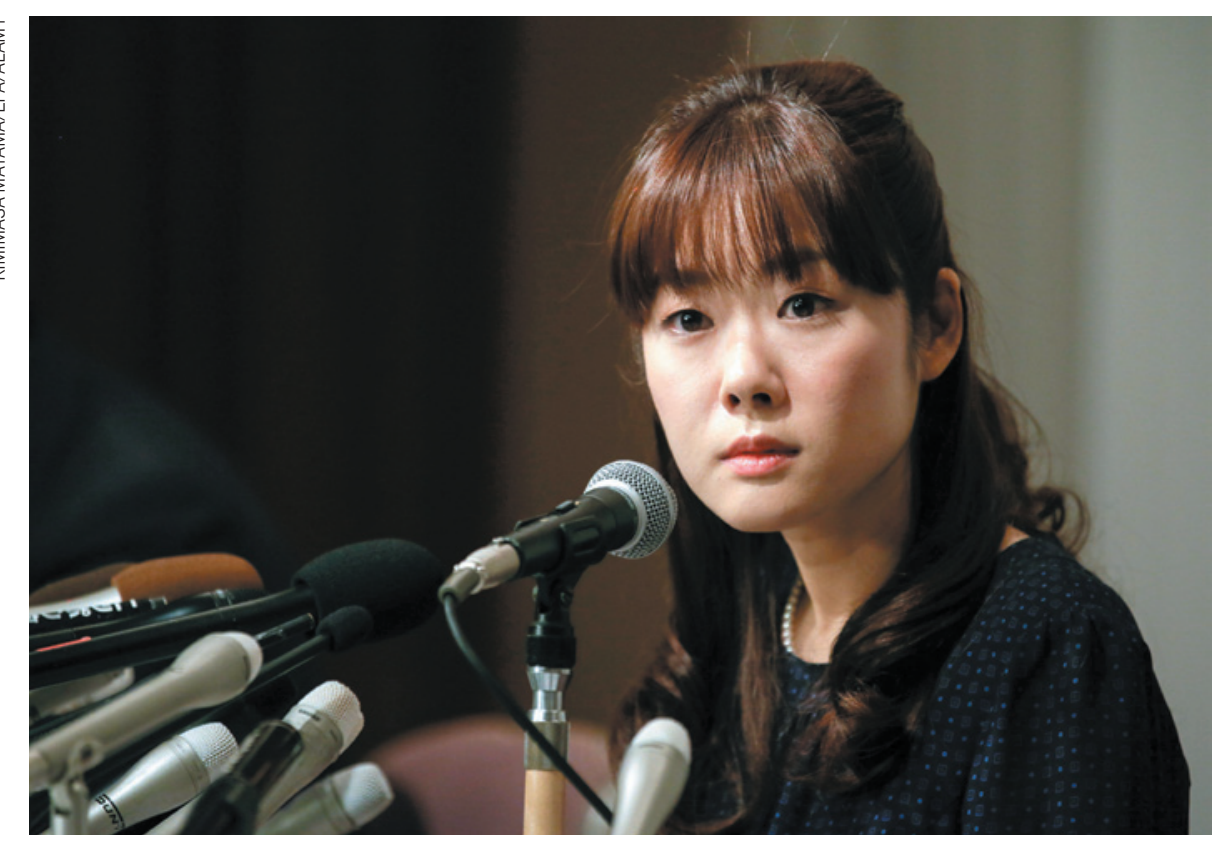

At a press conference last week, Haruko Obokata insisted that her contentious technique does work.

REPRODUCIBILITY

\title{
Biologist defiant over stem-cell method
}

\section{Japanese author of controversial papers denies wrongdoing and stands by results as testing of her protocol begins.}

\section{BY DAVID CYRANOSKI}

$\mathrm{T}$ he lead author of two hotly debated stem-cell papers made a tearful plea for forgiveness last week after her employer found her guilty of misconduct. Haruko Obokata, a researcher at the RIKEN Center for Developmental Biology (CDB) in Kobe, Japan, struggled to answer questions about errors in the papers, which described how simple stressors such as acid or pressure could reprogram mature cells into an embryonic-like state. But that did not stop her from insisting that the reports were not fraudulent and that the phenomenon described in them is real.

Her comments have left observers wondering about the outcome of a controversy that has raged since the papers were published in Nature in January ${ }^{1,2}$. Clarity on the claimed creation of STAP cells (for stimulus-triggered acquisition of pluripotency) now awaits three key events, all expected in the next few months. Stem-cell scientists hope that one of these - a replication attempt based on Obokata's protocol, by Hitoshi Niwa, a co-author of the papers who also works at the $\mathrm{CDB}$ - will be conclusive.

"This looks like a rigorous protocol that hopefully will settle the question of whether pluripotent STAP cells can be generated or not," says Rudolf Jaenisch, a stem-cell biologist at the Whitehead Institute for Biomedical Research in Cambridge, Massachusetts, who was shown Niwa's protocol by Nature. (Nature's news and comment team is editorially independent of its research editorial team.)

Problems with the papers, including accusations that Obokata had plagiarized passages of text and used duplicated images, arose soon after publication. Moreover, other groups said that they were unable to reproduce the results.

RIKEN decided to investigate, and on 1 April reported a number of uncomfortable findings (see Nature http://doi.org/sbb; 2014). Two problems were deemed misconduct: the re-use of an image that Obokata had included in her 2011 doctoral dissertation to describe different kinds of cells from those described in the STAP papers, and an image of an electrophoresis gel that had been spliced into another image, making it appear to be part of a different experiment.

Obokata fought back. In a statement on 1 April, she accused the RIKEN committee of giving her no chance to explain how those mistakes were made. Then, on 8 April, she submitted an appeal asking RIKEN to withdraw the charges and assemble another committee to investigate. At a press conference she held on 9 April, she passionately made her case and stated that she had succeeded in creating STAP cells more than 200 times. She blamed the misconduct findings on personal failings. "My immaturity and lack of training, it's really shameful," she said. "But with my lawyer's help, I do think I'll be able to dispel these suspicions."

RIKEN has 50 days to determine whether its original misconduct findings should be upheld. But, either way, the committee has made it clear that its conclusions do not address the matter of whether the experimental results were valid.

Weighty evidence on that point could come as early as this summer. Teruhiko Wakayama at the University of Yamanashi, Japan, a co-author on the papers, has sent eight supposed STAP stemcell lines to an undisclosed genetic-testing centre to determine whether they could have been produced by contamination rather than stress. Because several mice were used in the work, one would expect to see genetic differences between the STAP lines - and for those differences to correspond to the animals from which the cells came. But if all the lines are genetically identical, it would suggest that the original results came about through contamination.

Evidence on whether STAP works at all may emerge even earlier. On 1 April, Niwa began tests approved by RIKEN that will follow the STAP method. He will use the same mouse cell types (lymphocytes) that Obokata did, as well as other kinds of mature mouse cells, and will perform some additional tests to try to trace the conversion. The work is expected to take a year, but an interim report will be released around the end of July. This could show whether the cells have passed the first crucial stages of STAP conversion. RIKEN says that Obokata will not be a member of the re-evaluation team, although she might be consulted on technical details.

Some researchers are hopeful that Niwa's study will clear up the controversy. "Hitoshi Niwa's reputation is stellar," says Hans Schöler of the Max Planck Institute for Molecular Biomedicine in Münster, Germany. He suggests that Niwa should involve Obokata, "following her step by step and letting her make all the solutions with his reagents in his presence, to see if she forgot to mention a critical step".

Josh Brickman, of the Danish Stem Cell Center at the University of Copenhagen, says that although negative results should settle the issue, "a positive replication, or worse, a limited positive replication" would just lead to more questions. "I would not be surprised if stress-induced reprogramming ends up being partially reproducible - an extremely rare and fickle process," he says. "If this is the case, it may become increasingly difficult to determine exactly what was right in the original papers."

1. Obokata, H. et al. Nature 505, 641-647 (2014)

2. Obokata, H. et al. Nature 505, 676-680 (2014). 